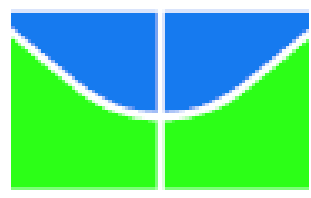

UNIVERSIDADE DE BRASÍLIA

Faculdade de Educação - UAB / UNB / MEC / SECAD

Curso de Especialização em Educação na

Diversidade e Cidadania, com Ênfase em EJA

DANIELA PASSOS GIACOMAZZO

IZABEL CHRISTINA DE ALMEIDA MENDES

\title{
CONTEÚDOS DE GEOGRAFIA E HISTÓRIA PARA O 20 SEGMENTO DA EDUCAÇÃO DE JOVENS E ADULTOS
}

BRASÍLIA, DF

Julho/2010 
UNIVERSIDADE DE BRASÍLIA

Faculdade de Educação - UAB / UNB / MEC / SECAD

Curso de Especialização em Educação na

Diversidade e Cidadania com Ênfase em EJA

\title{
CONTEÚDOS DE GEOGRAFIA E HISTÓRIA PARA O 2 SEGMENTO DA EDUCAÇÃO DE JOVENS E ADULTOS
}

\author{
DANIELA PASSOS GIACOMAZZO \\ IZABEL CHRISTINA DE ALMEIDA MENDES
}

PROFESSOR ORIENTADOR: RENATO HILÁRIO DOS REIS

TUTORA ORIENTADORA: LEILA MARIA DE JESUS OLIVEIRA

PROJETO DE INTERVENÇÃO LOCAL

BRASÍLIA, DF

Julho/2010 
UNIVERSIDADE DE BRASÍLIA

Faculdade de Educação - UAB / UNB / MEC / SECAD

Curso de Especialização em Educação na

Diversidade e Cidadania, com Ênfase em EJA

DANIELA PASSOS GIACOMAZZO

IZABEL CHRISTINA DE ALMEIDA MENDES

\section{CONTEÚDOS DE GEOGRAFIA E HISTÓRIA PARA O 2 SEGMENTO DA EDUCAÇÃO DE JOVENS E ADULTOS}

Projeto de conclusão do Curso de Especialização na Diversidade e Cidadania, com Ênfase na EJA, como parte dos requisitos necessários para obtenção do grau de Especialista na

Educação de Jovens e Adultos

RENATO HILÁRIO DOS REIS

Professor Orientador

LEILA MARIA DE JESUS OLIVEIRA

Tutor Orientador

CLAÚDIA DENIS ALVES DA PAZ

Avaliador Externo

BRASÍLIA, DF

Julho/2010 
"Aprendizagem é um fenômeno que surge dentro do indivíduo como resultado dos esforços desse mesmo indivíduo."

Idalberto Chiavenato 


\section{RESUMO}

Reconhecidamente a educação é o instrumento mais eficaz para se moldar valores, comportamentos, habilidades e atitudes. Diante dos processos de evidente globalização do planeta devemos preparar os alunos para uma sociedade multicultural. Neste sentido, uma das inquietações presentes na construção do Projeto de Intervenção Local (PIL) foi a necessidade de responder a um grande vácuo existente na Educação de Jovens e Adultos (EJA), qual seja, a falta de um currículo específico para atender às necessidades específicas dos alunos trabalhadores, de forma a integrá-los ao mundo trabalho e à sociedade em que vivem. Para que haja uma efetiva integração entre a EJA, o mundo do trabalho e a sociedade, é preciso que educadores e alunos se indaguem: como efetuar essa integração na EJA? Necessário se faz compreender o mundo do trabalho como eixo gerador da produção de outros conhecimentos, ou seja, como contribuir para que o campo de discussão do emprego, do subemprego e do desemprego faça-se presente de forma efetiva na EJA? Como enfrentar o racismo, sexismo e a exclusão de pessoas portadoras de necessidades especiais? Não é preciso viver a situação da discriminação para defender as suas causas, é necessário compreender o mal que uma sociedade faz a si própria quando fecha os olhos para a segregação e a exclusão de um determinado grupo de pessoas e para as conseqüências que a falta de informação pode gerar. A ação prática depende da vontade de buscar alternativas possíveis, inteligentes e viáveis partindo do lugar de onde nós estamos. Ao trabalhar com a EJA, observa-se a carência dos alunos desse segmento quanto ao conhecimento de assuntos atuais e polêmicos, que são abordados em sala de aula. Assuntos que julgamos de relevância para o crescimento profissional e o exercício da cidadania no cotidiano. Cada módulo proposto pelo curso veio a somar na escolha dos temas que objetivamos abordar com nossos alunos. Temas como a Diversidade Cultural, Etnia, Inclusão Social, Políticas Públicas, entre outros, são de grande relevância em nossa sociedade e de grande interesse dos alunos. Assim, diante de tantos temas, tivemos que agrupá-los de forma concisa, devido a premência de tempo e também objetivando não exagerar nos dispêndios com material didático a ser utilizado. Esperamos obter êxito com a aplicação do PIL e melhorar paulatinamente a cada semestre. Neste sentido, vislumbramos levar os alunos a participar efetivamente da sociedade em que vivem, com consciência dos seus direitos e deveres como cidadãos, com consciência política, incentivando ainda, a adesão de outras disciplinas ao PIL.

Palavras-chave: Cidadania, Currículo, Diversidade, EJA e Trabalhador. 


\section{LISTA DE ILUSTRAÇÕES}

Ilustração

pág.

Ilustração 1 - Fotografia dos alunos do $8^{\circ}$ semestre do ano de 2009, da EJA - CEF 01 - Paranoá / DF 


\section{LISTA DE TABELAS}

Tabelas

pág.

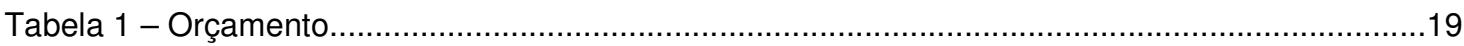




\section{LISTA DE QUADROS}

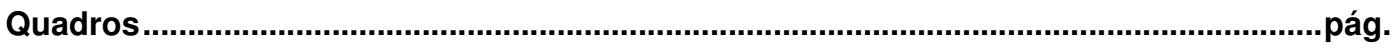

Quadro 1 - Atividades e Responsabilidades ................................................................

Quadro 2 - Conteúdos de História para EJA - ${ }^{\circ}$ segmento .............................................15

Quadro 3 - Conteúdos de Geografia para EJA - $2^{\circ}$ segmento ........................................... 16 


\section{SUMÁRIO}

1. Dados de identificação dos proponentes ................................................... 9

2. Dados de identificação do Projeto.............................................................. 9

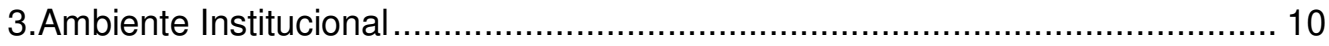

4. Justificativa e caracterização do problema...................................................... 11

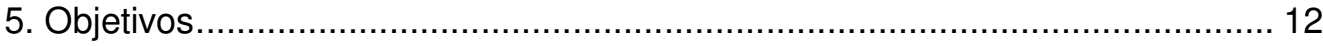

6. Atividades / Responsabilidades ....................................................... 13

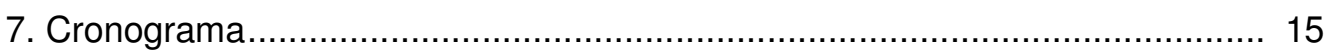

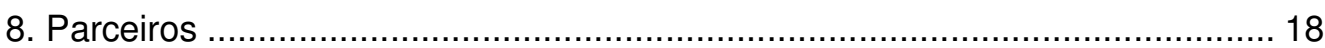

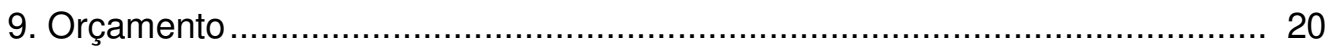

10. Acompanhamento e Avaliação............................................................ 20

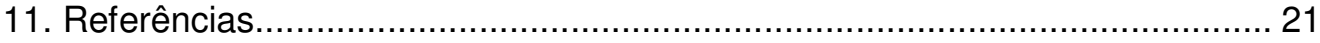

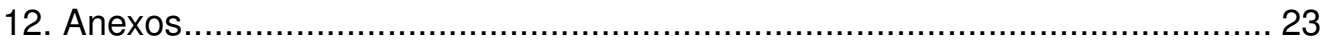




\section{PROJETO DE INTERVENÇÃO LOCAL - PIL}

\section{DADOS DE IDENTIFICAÇÃO DOS PROPONENTES:}

1.1 - Nomes: Izabel Christina de Almeida Mendes - Turma: A - Telefones: 3349-6599 e 8481-1640, e-mail: izatinaa@gmail.com; e

Daniela Passos Giacomazzo - Turma: A - Telefones: 3264-7787 e

9955-7993, e-mail: dgiacomazzo@hotmail.com

\section{DADOS DE IDENTIFICAÇÃO DO PROJETO:}

$2.1-$ Título

Conteúdos de Geografia e História para o $2^{\circ}$ segmento da Educação de Jovens e Adultos

2.2 - Área de abrangência

Abrangência local, $2^{\circ}$ Segmento - Ensino Fundamental, séries finais, $1^{\text {a }}$ a $4^{\underline{a}}$ etapa do $2^{\circ}$ segmento, o que corresponde de $5^{\mathrm{a}}$ a $8^{\mathrm{a}}$ Série do ensino regular.

2.3 - Instituição

Centro de Ensino Fundamental 01 (CEF 01) - Paranoá

Endereço: Quadra 03, Área Especial, lote 06 - Paranoá/ DF

Instância institucional de decisão: Governo, Secretaria de Educação, Conselho de Educação, todos do Distrito Federal.

2.4 - Alunos de ensino fundamental que cursam a EJA

O público ao qual se destina o Projeto de Intervenção Local (PIL) está direcionado aos alunos que cursam a Educação de Jovens e Adultos (EJA), $2^{\circ}$ Segmento, noturno, jovens e adultos trabalhadores, todos do CEF 01, do Paranoá.

A aplicabilidade do PIL busca a integração desses alunos à sociedade de forma participativa, visando interesses individuais, profissionais e a construção de uma sociedade mais igualitária e menos opressora. 
Com 011 PIL, esses alunos compreenderão que várias situações que vivenciam diariamente podem se modificar a partir da conscientização de cada indivíduo sobre os diferentes temas propostos no currículo.

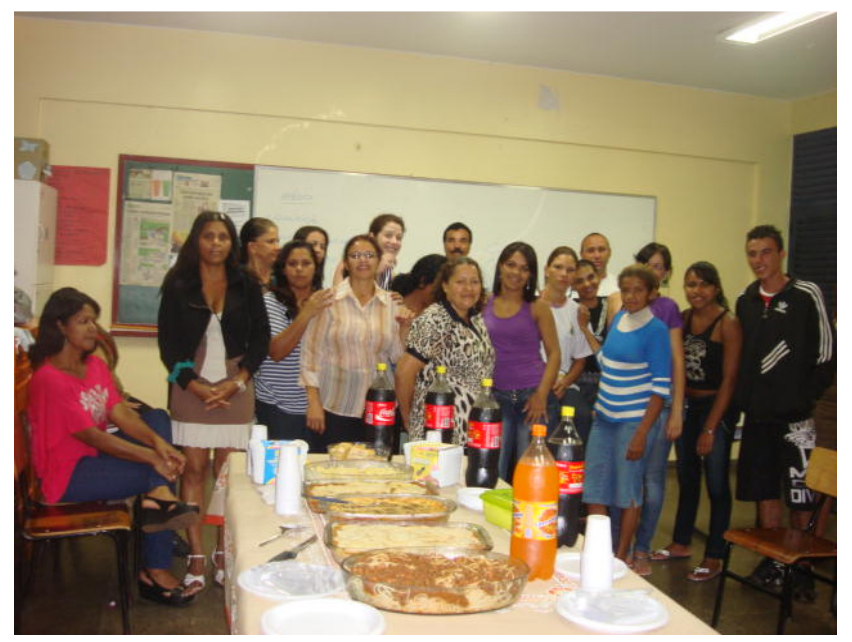

Ilustração 1 - Fotografia dos alunos do $8^{\circ}$ semestre do ano de 2009, da EJA - CEF 01 - Paranoá / DF.

2.5 - Período de execução

Início: Julho/2010; Término: dezembro/2010

\section{AMBIENTE INSTITUCIONAL}

O Centro de Ensino Fundamental 01 do Paranoá foi construído em 1988 e durante muitos anos funcionou precariamente, sendo conhecido como "Cajinho".

As reformas estruturais eram necessárias para atender a demanda de estudantes que crescia a cada ano com a expansão da cidade do Paranoá.

Devido a essa situação, a escola foi demolida e passou a funcionar precariamente no Centro de Ensino Fundamental 07 de Brasília, na 912 Norte.

No início do ano letivo de 2005 , os alunos foram novamente transferidos em caráter provisório, para a Escola Normal de Brasília, na Asa Sul. Mesmo com a obra da escola não concluída, em março do mesmo ano, houve a ocupação do novo prédio. Entretanto, somente em setembro de 2005, a escola foi totalmente entregue à comunidade.

Hoje, conta com uma estrutura física privilegiada e um amplo espaço físico para o desenvolvimento de atividades pedagógicas. Funciona em três turnos nas seguintes modalidades: 
a) Matutino - com turmas de $6^{\underline{a}}$ a $8^{\underline{a}}$ séries, de correção de fluxo idade / série e de Ensino Especial;

b) Vespertino - com turmas de 5a e 6aㅗ séries e de Ensino Especial;

c) Noturno - com turmas do $1^{\circ}$ e $2^{\circ}$ segmento da EJA.

Dentre os Projetos Políticos Pedagógicos realizados nesta escola, destacamos o de oficinas temáticas: realizado semanalmente, cujas temáticas abordavam interesses dos alunos em contextos extracurriculares, com temas de influência em diferentes áreas trabalhista, econômica, artística, social, cultural ou lúdica. O aluno, não só utilizava seu tempo para acessar a educação formal, mas também para se aprofundar em áreas de interesses subjetivos.

\section{JUSTIFICATIVA E CARACTERIZAÇÃO DO PROBLEMA}

Um problema presente na EJA diz respeito à escassez e à deficiência do conteúdo destinado a este ensino. Recebemos, em nossa escola, pessoas diversas que já possuem certos conhecimentos e experiências de vida; são jovens e adultos que por inúmeros motivos não tiveram acesso ao ensino regular. Ingressam no ambiente escolar com necessidades educacionais especiais, já que trabalham, são chefes de família, ou ainda desempregados buscando mais e melhores oportunidades de trabalho.

Estes jovens e adultos trazem também consigo preconceitos e desconhecimentos de vários assuntos, que são latentes em nossa sociedade e que precisam ser esclarecidos. Sobre o mundo indígena e os Quilombolas, por exemplo. Segundo Luciano (2006):

Um mundo que se alto define como moderno e civilizado não pode aceitar conviver com essa ausência de democracia racial, cultural e política. Como se pode ser civilizado se não se aceita conviver com outras civilizações? Como se pode ser culto e sábio se não se conhece - e o que é bem pior não se aceita conhecer outras culturas e sabedorias? Enquanto isso não acontece, continuamos convivendo com as contradições em relação aos povos indígenas.

Outro aspecto que se caracteriza como problema a ser esclarecido é a falta de respeito à cultura destes povos, como negros e índios, pois o que define os grupos étnicos não é apenas a preservação das tradições de seus antepassados, mas principalmente: "pela maneira como cada grupo molda o espaço em que vive e que se difere das formas tradicionais de apropriação dos recursos da natureza"; como defende SUNDFELD (2002, p. 78).

Destarte, a orientação curricular proposta pela Secretaria de Educação do Distrito Federal para o ensino regular de Geografia e História, utilizada na EJA, não proporciona uma sintonia com a realidade cultural, etária e profissional de nossos alunos que são 
trabalhadores, desempregados, jovens, idosos, pais de família, portadores de necessidades especiais - enfim, pessoas que buscam uma educação inclusiva no contexto de uma sociedade democrática, com igualdade de oportunidade independente de raça, idade, status social ou orientação sexual.

Paulo Freire coloca: Freire (2001) coloca: "O jovem e o adulto, quando ingressam na escola, já possuem conhecimentos diversos sobre o mundo, adquiridos em situações escolares anteriores e/ou na vida pessoal. Assim, para atingir um ensino eficaz, a Educação de Jovens e Adultos deve seguir uma linha de raciocínio semelhante à da educação popular; isto é, uma educação que envolve questões políticas e, não apenas, transmite conteúdos. Para isso, a história de cada aluno, as suas necessidades e o seu cotidiano deverão ser necessariamente levados em consideração na construção do currículo escolar."

Cientes dessa realidade e tendo consciência da importância de uma matriz curricular de qualidade e específica para professor e alunos, propusemos, neste projeto, adequar o conteúdo tanto aos interesses e à realidade cultural e subjetiva dos alunos quanto às exigências do mercado de trabalho. Um conteúdo que contemple conhecimentos atuais, essenciais e presentes na realidade dos educandos, considerando o contexto social, profissional, histórico, econômico, geográfico e político nos quais estão inseridos. Essa matriz será integrada aos conceitos tradicionais e indispensáveis para a construção do conhecimento de Geografia e História do respectivo semestre, sem prejuízo do currículo tradicional, o qual viabiliza o acesso dos alunos ao ensino médio, prestação de exames para acesso à faculdade.

\section{OBJETIVOS:}

\section{1- Objetivo geral}

Introduzir no conteúdo de Geografia e História, trabalhado com a EJA do 2ํㅗ segmento, temas direcionados à diversidade cultural, ao mundo de trabalho e à cidadania.

\section{2 - Objetivos específicos}

- Motivar a participação espontânea dos alunos em aula, com suas experiências pessoais;

- Incentivar a participação cidadã dos alunos na sociedade em que estão inseridos;

- Buscar mudanças de atitudes no convívio diário e social dos alunos;

- Explicar que os avanços tecnológicos e as transformações socioculturais são conquistas ainda não usufruídas por todos e por isso há a necessidade de democratizá-las; e 
- Desenvolver conhecimentos sobre a conjuntura atual nas áreas política, social, econômica e cultural.

\section{ATIVIDADES / RESPONSABILIDADES:}

$O$ quadro seguinte demonstra as atividades que serão desenvolvidas ao longo da implantação do PIL e suas respectivas responsabilidades. Atividades que englobam desde trabalhos teóricos a trabalhos de campo. Neste momento, estão envolvidos os atores diretamente relacionados ao projeto, ou seja, professores e alunos.

\begin{tabular}{|l|l|}
\hline Atividades & Responsabilidades \\
\hline $\begin{array}{l}\text { Interpretações de textos sobre a importância de assuntos } \\
\text { relacionados à História e Geografia no cotidiano. }\end{array}$ & Professores e alunos \\
\hline $\begin{array}{l}\text { Entrevista com as pessoas da comunidade sobre a } \\
\text { satisfação quanto à aplicação de políticas públicas atinentes } \\
\text { a inclusão social. }\end{array}$ & Alunos \\
\hline $\begin{array}{l}\text { Elaboração de problemas relacionados à exclusão social. } \\
\text { Realização de pesquisa de campo (questionário) sobre } \\
\text { diversidade cultural, no tocante a problemas enfrentados pela } \\
\text { comunidade do Paranoá quanto à existência de } \\
\text { preconceitos. }\end{array}$ & Alunos \\
\hline $\begin{array}{l}\text { Coleta de dados sobre a influência da densidade } \\
\text { demográfica na vida da comunidade. }\end{array}$ & Alunos \\
\hline $\begin{array}{l}\text { Identificação de direitos e deveres atribuídos aos cidadãos e } \\
\text { à estrutura sócio-política e administrativa do Distrito Federal. }\end{array}$ & Professores e alunos \\
\hline $\begin{array}{l}\text { Debate sobre a aplicação dos recursos públicos destinados a } \\
\text { educação. }\end{array}$ & Professores e alunos \\
\hline $\begin{array}{l}\text { Utilização de textos para concatenar o processo histórico e } \\
\text { geográfico passado a assuntos e problemas atuais. }\end{array}$ & Professores e alunos \\
Quadro 1-Atividades e Responsabilidades & \\
\hline
\end{tabular}




\section{CRONOGRAMA: DISCIPLINA HISTÓRIA/GEOGRAFIA}

\subsection{Disciplina - História}

\begin{tabular}{|c|c|c|c|}
\hline Público alvo & Conteúdo & Objetivos específicos & Duração \\
\hline $\begin{array}{l}2^{\circ} \text { segmento - } \\
5^{\circ} \text { semestre }\end{array}$ & $\begin{array}{l}{ }^{*} \text { Minha história; } \\
{ }^{*} \text { Em busca das } \\
\text { origens; }\end{array}$ & $\begin{array}{l}\text { - Questionar a realidade do meio em } \\
\text { que vive; } \\
\text { - Identificar os seus problemas; } \\
\text { - Refletir sobre possíveis soluções } \\
\text { dos problemas identificados; }\end{array}$ & $\begin{array}{l}02 A g 02010 \\
\text { a } \\
27 \text { Ago2010 }\end{array}$ \\
\hline $\begin{array}{l}2^{\circ} \text { segmento - } \\
5^{\circ} \text { semestre }\end{array}$ & $\begin{array}{l}\text { * Diversidade } \\
\text { cultural: } \\
\text { - Povo indígenas; } \\
\text { - Negros }\end{array}$ & $\begin{array}{l}\text { Reconhecer as mudanças e } \\
\text { permanências nas vivências } \\
\text { humanas; } \\
\text { - Respeitar os valores do pluralismo; }\end{array}$ & $\begin{array}{l}30 \text { Ago2010 } \\
\text { a } \\
290 u t 2010\end{array}$ \\
\hline $\begin{array}{l}2^{\circ} \text { segmento - } \\
5^{\circ} \text { semestre }\end{array}$ & $\begin{array}{l}\text { * História do } \\
\text { Paranoá }\end{array}$ & $\begin{array}{l}\text { - Conhecer e respeitar o modo de } \\
\text { vida de diferentes grupos sociais em } \\
\text { diversos tempos e espaços. }\end{array}$ & $\begin{array}{l}\text { 01Nov2010 } \\
\text { a } \\
\text { 26Nov2010 }\end{array}$ \\
\hline $\begin{array}{l}2^{\circ} \text { segmento - } \\
6^{\circ} \text { semestre }\end{array}$ & $\begin{array}{l}\text { * Direitos do } \\
\text { cidadão brasileiro; } \\
\text { - Constituição; } \\
\text { - Direitos e } \\
\text { deveres; }\end{array}$ & $\begin{array}{l}\text { - Desempenhar, de modo } \\
\text { consciente, a sua cidadania, por } \\
\text { intermédio do conhecimento dos } \\
\text { seus direitos e deveres; }\end{array}$ & $\begin{array}{l}\text { 02Ago2010 } \\
\text { a } \\
\text { 24Set2010 }\end{array}$ \\
\hline $\begin{array}{l}2^{\circ} \text { segmento - } \\
6^{\circ} \text { semestre }\end{array}$ & $\begin{array}{l}\text { - Cidadania; } \\
\text { - Ações cidadãs. }\end{array}$ & $\begin{array}{l}\text { - Desenvolver valores e conceitos } \\
\text { que o ajudem a compreender } \\
\text { criticamente a realidade em que } \\
\text { vivem, inserindo-se na sociedade de } \\
\text { forma consciente e participativa. }\end{array}$ & $\begin{array}{l}\text { 04Out2010 } \\
\text { a } \\
\text { 26Nov2010 }\end{array}$ \\
\hline $\begin{array}{l}2^{\circ} \text { segmento - } \\
7^{\circ} \text { semestre }\end{array}$ & $\begin{array}{l}\text { * A estrutura dos } \\
\text { Poderes: } \\
\text { - Legislativo; } \\
\text { - Executivo; } \\
\text { - Judiciário }\end{array}$ & $\begin{array}{l}\text { - Conhecer a aplicabilidade das } \\
\text { principais leis que regem o país. }\end{array}$ & $\begin{array}{l}\text { 04Out2010 } \\
\text { a } \\
\text { 26Nov2010 }\end{array}$ \\
\hline
\end{tabular}




\begin{tabular}{|c|c|c|c|}
\hline Público alvo & Conteúdo & Objetivos específicos & Duração \\
\hline $\begin{array}{l}2^{\circ} \text { segmento - } \\
7^{\circ} \text { semestre }\end{array}$ & $\begin{array}{l}\text { * A República } \\
\text { Federativa do } \\
\text { Brasil: } \\
\text { - Estrutura; } \\
\text { - Símbolos } \\
\text { Nacionais e do } \\
\text { Distrito Federal; }\end{array}$ & $\begin{array}{l}\text { - Conhecer a organização social do } \\
\text { país; } \\
\text { - Identificar os símbolos nacionais. }\end{array}$ & $\begin{array}{l}02 \text { Ago2010 } \\
\text { a } \\
\text { 24Set2010 }\end{array}$ \\
\hline $\begin{array}{l}2^{\circ} \text { segmento - } \\
8^{\circ} \text { semestre }\end{array}$ & $\begin{array}{l}\text { * Movimentos } \\
\text { sociais e ONG's: }\end{array}$ & $\begin{array}{l}\text { - Compreender as relações sociais e } \\
\text { atuar sobre elas como cidadãos; } \\
\text { - Conhecer e estimular a reflexão } \\
\text { sobre o lugar que vive como parte } \\
\text { integrante da história; }\end{array}$ & $\begin{array}{l}\text { 02Ago2010 } \\
\text { a } \\
\text { 03Set2010 }\end{array}$ \\
\hline $\begin{array}{l}2^{\circ} \text { segmento - } \\
8^{\circ} \text { semestre }\end{array}$ & $\begin{array}{ll}\text { * História da } & \text { da } \\
\text { construção } & \text { de } \\
\text { Brasília: } & \\
\text { - Interiorização; } \\
\text { Missão Cruls; } \\
\text { - Brasília atual. }\end{array}$ & $\begin{array}{l}\text { - Identificar os impactos do rápido } \\
\text { desenvolvimento da cidade na vida } \\
\text { das pessoas. }\end{array}$ & $\begin{array}{l}\text { 13Set2010 } \\
\text { a } \\
26 \text { Nov2010 }\end{array}$ \\
\hline
\end{tabular}

7.2 Disciplina - Geografia

\begin{tabular}{|c|c|c|c|}
\hline Público alvo & Conteúdo & Objetivos específicos & Duração \\
\hline $\begin{array}{l}2^{\circ} \text { segmento - } \\
5^{\circ} \text { semestre }\end{array}$ & $\begin{array}{l}\text { * Patrimônio } \\
\text { cultural }\end{array}$ & $\begin{array}{l}\text { - Reconhecer a diversidade } \\
\text { cultural; } \\
\text { - Respeitar, valorizar e preservar o } \\
\text { patrimônio sociocultural; } \\
\text { - Fortalecer os sentimentos de } \\
\text { identidade e cidadania; } \\
\text { - Identificar os monumentos e } \\
\text { atrações turísticas do DF. }\end{array}$ & $\begin{array}{l}02 A g 02010 \\
a \\
27 A g 02010\end{array}$ \\
\hline
\end{tabular}




\begin{tabular}{|c|c|c|c|}
\hline Público alvo & Conteúdo & Objetivos específicos & Duração \\
\hline $\begin{array}{l}2^{\circ} \text { segmento - } \\
5^{\circ} \text { semestre }\end{array}$ & $\begin{array}{l}\text { *Aspectos físicos, } \\
\text { socioeconômicos } \\
\text { e culturais do } \\
\text { Paranoá }\end{array}$ & $\begin{array}{l}\text { - Compreender o espaço físico do } \\
\text { Paranoá; } \\
\text { - Conhecer as características da } \\
\text { população do Paranoá; } \\
\text { - Analisar a principal atividade } \\
\text { econômica do Paranoá. }\end{array}$ & $\begin{array}{l}30 \mathrm{Ago} 2010 \\
\mathrm{a} \\
26 \text { Nov2010 }\end{array}$ \\
\hline $\begin{array}{l}2^{\circ} \text { segmento - } \\
6^{\circ} \text { semestre }\end{array}$ & $\begin{array}{l}\text { *Aspectos físicos, } \\
\text { políticos } \\
\text { econômicos do } \\
\text { DF }\end{array}$ & $\begin{array}{l}\text { - Conhecer o espaço físico do DF; } \\
\text { - Caracterizar o impacto antrópico } \\
\text { com a instalação da capital, as } \\
\text { migrações e a especulação } \\
\text { imobiliária; } \\
\text { - Identificar as atividades } \\
\text { econômicas em crescimento no } \\
\text { DF; Covolução } \\
\text { - Compreender a suas } \\
\text { administrativa do DF e suaridades. } \\
\text { peculiaria }\end{array}$ & $\begin{array}{l}02 \text { Ago2010 } \\
\text { a } \\
14 \text { Out2010 }\end{array}$ \\
\hline $\begin{array}{l}2^{\circ} \text { segmento - } \\
6^{\circ} \text { semestre }\end{array}$ & ${ }^{\star}$ Emprego & $\begin{array}{l}\text { - Analisar as transformações na } \\
\text { estrutura de emprego do país sob o } \\
\text { ponto de vista da empregabilidade } \\
\text { e do desemprego na época da } \\
\text { revolução tecno-científica; } \\
\text { - Perceber o aumento do emprego } \\
\text { informal em relação ao formal; } \\
\text { - Analisar as causas e } \\
\text { conseqüências da informalidade. }\end{array}$ & $\begin{array}{l}\text { 18Out2010 } \\
\text { a } \\
26 \text { Nov2010 }\end{array}$ \\
\hline $\begin{array}{l}2^{\circ} \text { segmento - } \\
7^{\circ} \text { semestre }\end{array}$ & ${ }^{*}$ Reformas & $\begin{array}{l}\text { - Conhecer as propostas de } \\
\text { reformas política, tributária, } \\
\text { previdenciária e trabalhista; } \\
\text { - Analisar os pontos negativos e } \\
\text { positivos das mudanças propostas } \\
\text { nas relações entre os cidadãos e o } \\
\text { Estado; }\end{array}$ & $\begin{array}{l}02 \text { Ago2010 } \\
\text { a } \\
26 \text { Nov2010 }\end{array}$ \\
\hline
\end{tabular}




\begin{tabular}{|c|c|c|c|}
\hline Público alvo & Conteúdo & Objetivos específicos & Duração \\
\hline $\begin{array}{l}2^{\circ} \text { segmento - } \\
8^{\circ} \text { semestre }\end{array}$ & $\begin{array}{ll}{ }^{*} \text { Matriz } & \text { de } \\
\text { transporte } & \end{array}$ & $\begin{array}{l}\text { - Compreender a inadequação do } \\
\text { sistema de transportes brasileiro; } \\
\text { - Identificar as variáveis a serem } \\
\text { consideradas no transporte de } \\
\text { mercadorias; } \\
\text { - Buscar soluções para melhoria e } \\
\text { diminuição do custo no transporte } \\
\text { de mercadorias. }\end{array}$ & $\begin{array}{l}02 \mathrm{Ago} 2010 \\
\text { a } \\
24 \text { Set2010 }\end{array}$ \\
\hline $\begin{array}{l}2^{\circ} \text { segmento - } \\
8^{\circ} \text { semestre }\end{array}$ & ${ }^{*}$ Matriz de Energia & $\begin{array}{l}\text { - Reconhecer a importância da } \\
\text { diversificação da matriz de energia; } \\
\text { - compreender a necessidade do } \\
\text { equilíbrio da matriz energética e do } \\
\text { uso de fontes mais limpas e } \\
\text { renováveis. }\end{array}$ & $\begin{array}{l}27 \operatorname{Set} 2010 \\
a \\
26 \text { Nov2010 }\end{array}$ \\
\hline
\end{tabular}

Quadro 3 - Conteúdos de Geografia para a educação de jovens e adultos - $2^{\circ}$ segmento

Depois de cumprido o cronograma constante das tabelas acima (agosto a novembro / 2010) será proposto à direção da escola que este PIL passe a fazer parte do PPP da escola a partir do primeiro semestre letivo de 2011, objetivando abranger toda a classe docente da instituição, ampliando a interdisciplinaridade dos assuntos propostos.

\section{PARCEIROS}

A parceria acontecerá com os atores abaixo envolvidos, da forma que se segue:

- Direção da Escola: autorização e apoio para a aplicação do PIL, disponibilização dos meios auxiliares pedagógicos e reprodução de textos.

- Coordenadores pedagógicos: divulgação do PIL aos professores de outras disciplinas, por meio das coordenações.

- Palestrantes convidados: líderes comunitários, representantes de grupos raciais e pessoas de representatividade na sociedade do Paranoá.

- Comunidade: responder as entrevistas propostas.

- Professores da escola: professores de outras disciplinas convidados a participar das atividades do projeto, fomentando a interdisciplinaridade.

- Alunos da EJA: realizar pesquisas de campo e serem atores principais no processo de intervenção local. 
- Professores responsáveis pelo PIL: Coordenar e executar a aplicação do PIL.

Depois de implantado, o PIL terá, ainda, como parceiros, toda a classe docente da EJA, objetivando ampliar a interdisciplinaridade dos assuntos propostos.

9. ORÇAMENTO

\begin{tabular}{|c|c|}
\hline ELEMENTOS DE DESPESAS & $\begin{array}{r}\text { VALORES } \\
\text { Em R\$ }\end{array}$ \\
\hline Locação de documentários (filmes) & 100,00 \\
\hline Aquisição de livros e publicações & 275,00 \\
\hline $\begin{array}{llll}\text { Assinatura semestral da } & \text { revista } \\
\text { Atualidades } & & & \end{array}$ & 39,80 \\
\hline $\begin{array}{l}\text { Assinatura anual da revista Aventuras } \\
\text { na História }\end{array}$ & 131,00 \\
\hline $\begin{array}{l}\text { Assinatura anual da revista Super } \\
\text { Interessante }\end{array}$ & 138,70 \\
\hline Transportes de palestrantes & 124,00 \\
\hline $\begin{array}{l}\text { Reprodução de questionários para } \\
\text { entrevistas }\end{array}$ & 500,00 \\
\hline Reprodução de textos pela escola & 500,00 \\
\hline
\end{tabular}

10. ACOMPANHAMENTO E AVALIAÇÃO:

O acompanhamento e avaliação será uma etapa fundamental para fornecer informações sobre a aplicação do projeto. Esses serão efetuados por meio do alcance, por parte dos temas apresentados, dos objetivos propostos, com base nas avaliações efetuadas. Para tanto usaremos de questionários, entrevistas e uma ficha de avaliação. Essa ficha está representada em anexo. 


\section{REFERÊNCIAS}

AVENTURAS na história. São Paulo: Abril, ed. mensais.

CONSTITUIÇÃO da República Federativa do Brasil. 42. ed. atual. e aum. São Paulo: Saraiva 2009.

CRULS, Luiz. Relatório Cruls - Relatório da Comissão Exploradora do Planalto Central.

FREIRE, Paulo. Pedagogia do Oprimido. 17ª ed. Rio de Janeiro: Paz e Terra, 1987.

FREIRE, Paulo. Política e educação. 5. ed. São Paulo: São Paulo, 2001.

GUIMARÃES, Michele. As Práticas Educativas na Educação de Jovens e Adultos. Pedagogia em Foco. Petrópolis, 2002."

GUIA do estudante - Atualidades vestibular. São Paulo: Abril, ed. semestrais de 2007 a 2010.

LASSANCE, Adalberto. Brasília e Distrito Federal: Imperativos Institucionais. Brasília: Verano, 2002.

LASSANCE, Adalberto; LOPES, Cleusa Nunes da Silva; SILVA, Denise Coelho; PEREIRA, Manoel Martins. Brasília: Capital do Brasil. Porfírio, 2003 (Edição e cultura pelo turismo).

LUCIANO, Gersem dos Santos. Baniwa - O Índio Brasileiro: o que você precisa saber sobre os povos indígenas no Brasil de hoje. Brasília: Ministério da Educação, Secretaria de Educação Continuada, Alfabetização e Diversidade: LACED/Museu Nacional, 2006. Coleção Educação para Todos, Vol. 12.

PAVIANE, Aldo. Brasília - Gestão Urbana: conflitos e cidadania. Brasília: UnB, 1990.

RESENDE, Márcia Spyer. A geografia do aluno trabalhador - caminhos para uma prática de ensino. São Paulo: Loyola, 1986. 
SUNDFELD, C.A 9org.) Comunidades Quilombolas: Direito a terra. Brasília: Fundação Cultural Palmares / Ed. Abaré, 2002.

VESENTINI, José Willian. A interiorização da Capital Federal na Perspectiva Geopolítica. São Paulo: Ática, 1986. 


\section{ANEXOS}

Anexo1: Modelo de ficha de avaliação

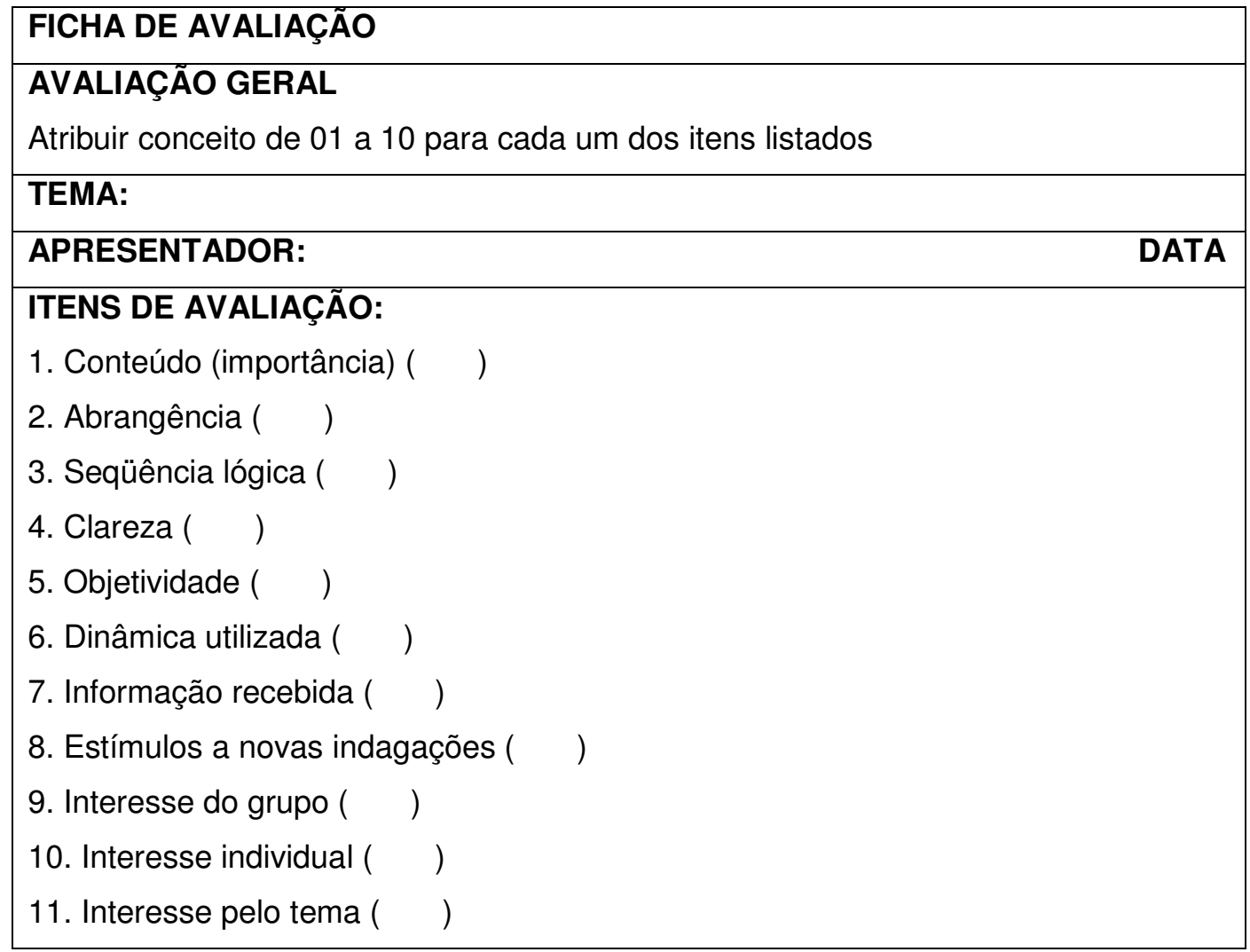

\section{Obs:}

a) Será considerado como objetivo atingido, se, em uma escala de 0 a 10 pontos o tema alcançar nota >= 7 em cada avaliação.

b) O projeto será avaliado e acompanhado pela equipe responsável pelos objetivos a serem atingidos, pelos autores, equipe da direção, professores, coordenadores, sendo utilizadas informações desta avaliação para a inserção de medidas corretivas para fins de melhoramento do projeto. 
Anexo 2: Fotografia dos alunos do $8^{\circ}$ semestre do ano de 2009, da Educação de Jovens e Adultos (EJA) - CEF 01.

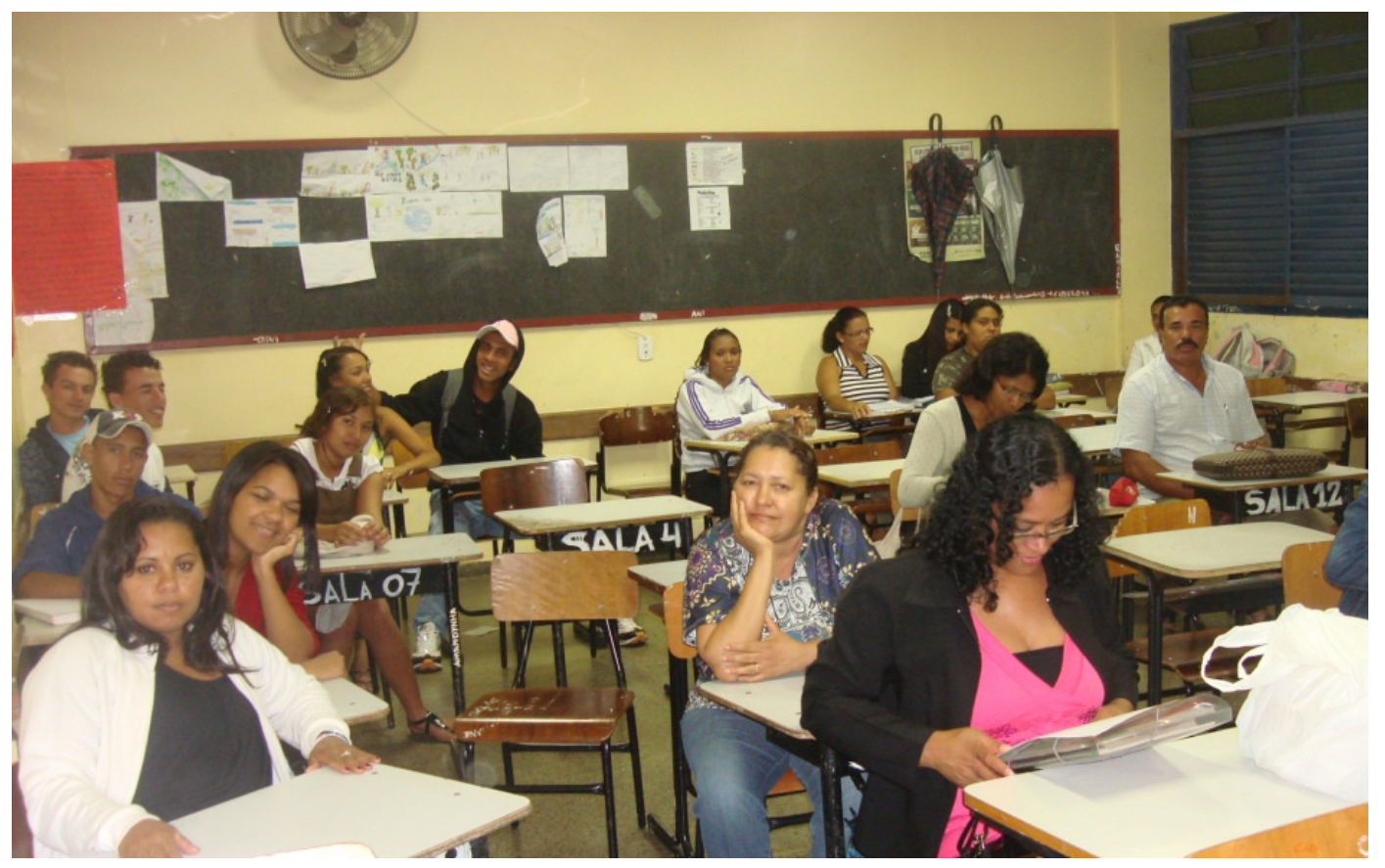

Anexo 3: Fotografia dos alunos do $8^{\circ}$ semestre de 2010, da Educação de Jovens e Adultos (EJA) - CEF 01.

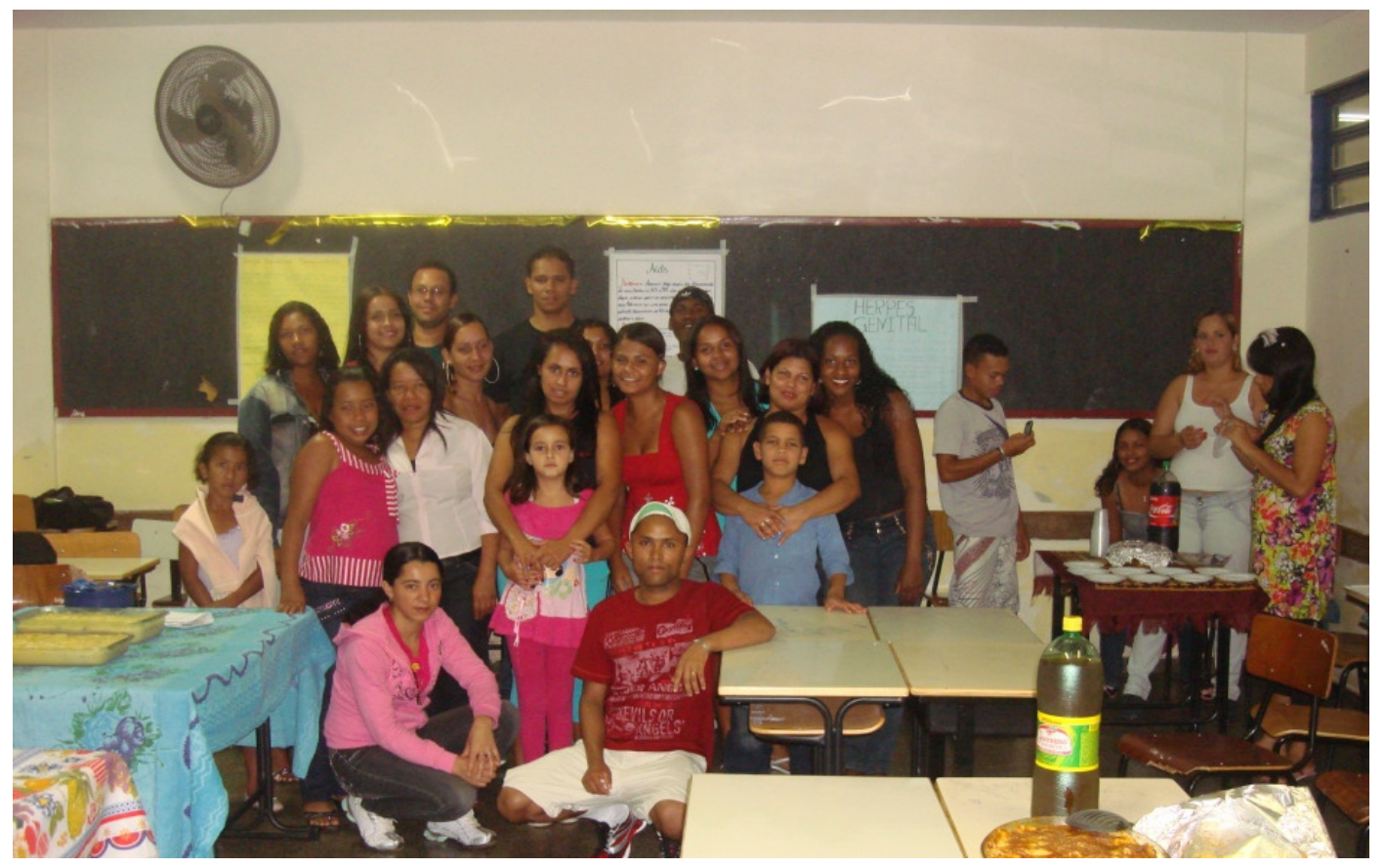

